\title{
CONTROVÉRSIAS SOCIOTÉCNICAS: UMA PROPOSTA DIDÁTICA PARA O ENSINO DE ENGENHARIA
}

\author{
CONTROVERSIAS SOCIOTÉCNICAS: UNA PROPUESTA DIDÁCTICA PARA LA \\ ENSEÑANZA DE INGENIERÍA
}

\author{
CONTROVERSY SOCIOTECHNICAL: A DIDACTIC PROPOSAL FOR ENGINEERING \\ EDUCATION
}

\author{
Vágner Ricardo de Araújo PEREIRA ${ }^{1}$ \\ Carlos Roberto Massao HAYASHI ${ }^{2}$
}

RESUMO: Neste artigo é apresentada uma proposta didática interdisciplinar com o objetivo de analisar questões sociotécnicas controversas em cursos de engenharia e contribuir para o desenvolvimento dos raciocínios crítico e reflexivo por meio da argumentação. A proposta foi elaborada com base em pesquisa realizada em uma turma de engenharia em horário extraclasse. A pesquisa foi delineada na forma de estudo de caso com análise qualitativa de dados. Os resultados indicam que os estudantes se envolvem e valorizam atividades interdisciplinares em sua formação profissional, entretanto, introduzi-las no currículo regular ainda é um desafio.

PALAVRAS-CHAVE: Ensino de engenharia. Interdisciplinaridade. Questões sociotécnicas controversas. Ciência, tecnologia e sociedade. Padrão de argumentos de Toulmin.

RESUMEN: En este artículo se presenta una propuesta didáctica interdisciplinaria con el objetivo de analizar cuestiones sociotécnicas controvertidas en cursos de ingeniería y contribuir al desarrollo de los razonamientos crítico y reflexivo por medio de la argumentación. La propuesta fue elaborada con base en investigación realizada en una clase de ingeniería en horario extra clase. La investigación fue delineada en la forma de estudio de caso con análisis cualitativo de datos. Los resultados indican que los estudiantes se involucran $y$ valoran actividades interdisciplinarias en su formación profesional, sin embargo, introducirlas en el currículo regular sigue siendo un desafío.

PALABRAS CLAVE: Enseñanza de ingeniería. Interdisciplinariedad. Cuestiones sociotécnicas controvertidas. Ciencia, tecnología y sociedad. Patrón de argumentos de Toulmin.

ABSTRACT: This paper presents an interdisciplinary didactic proposal with the aim of analyzing controversial sociotechnical issues in engineering education and contributes to the development of critical and reflexive reasoning through argumentation. The proposal was based on research done in an engineering class in extra-class hours. The research was outlined

\footnotetext{
${ }^{1}$ Instituto Federal de Educação, Ciência e Tecnologia de São Paulo (IFSP), Catanduva - SP - Brasil. Professor de Física. ORCID: <http://orcid.org/0000-0002-0168-8594>. E-mail: vagner.pereira@ifsp.edu.br

${ }^{2}$ Universidade Federal de São Carlos (UFSCar), São Carlos - SP - Brasil. Professor do PPGCTS. ORCID: <http://orcid.org/0000-0003-1481-5545>. E-mail: massao@ufscar.br
} 
as a case study with qualitative data analysis. The results indicate that students engage and value interdisciplinary activities in their professional qualification; however, introducing them into the regular curriculum is still a challenge.

KEYWORDS: Engineering education. Interdisciplinarity. Controversial sociotechnical issues. Science, technology and society. Toulmin's argument pattern.

\section{Introdução}

A proposta educacional apresentada pelas DCNs (Diretrizes Curriculares Nacionais) para os cursos de engenharia no Brasil (Brasil, 2002) incentiva uma formação além dos aspectos técnicos de cada área, pois considera essencial a discussão de questões interdisciplinares, com destaque aos aspectos humanísticos e aos raciocínios crítico e reflexivo, visando uma atuação profissional mais ampla no mundo contemporâneo. Tais habilidades e competências também estão presentes em diretrizes curriculares internacionais, por exemplo, no Criteria for Accrediting Engineering Programs (ABET, 2014).

O significado de interdisciplinaridade extrapola o da simples junção de disciplinas na matriz curricular dos cursos, pois requer uma atitude de ousadia e busca frente ao conhecimento (FAZENDA, 2008). Nesse sentido, Kline (2001) afirma que o campo de estudos CTS (Ciência, Tecnologia e Sociedade) pode contribuir significativamente para o ensino de engenharia, principalmente em relação às discussões sobre questões éticas, pois fornece subsídios analíticos mais profundos, complementando uma análise moral que a filosofia pode proporcionar.

Apesar das orientações das DCNs, a realidade da sala de aula em cursos de engenharia no país parece ainda não trilhar esse caminho, pois geralmente não estimula oportunidades para reflexões sobre questões interdisciplinares, sendo que na maioria das vezes o ensino é oferecido segundo uma metodologia tradicional, com ênfase na aprendizagem mecânica de conceitos técnicos e memorização. Além disso, é possível encontrar em diversas instituições de ensino algumas incongruências entre a vivência da sala de aula e os documentos que formalizam essa realidade, bem como divergências entre essa vivência e as necessidades da sociedade atual, incluindo aquelas do mercado de trabalho. Questões éticas, culturais e sociais muitas vezes são desconsideradas.

O ensino de engenharia no Brasil, de acordo com Bazzo (2010), não cumpre plenamente seus objetivos, pois não proporciona condições para que os estudantes adquiram as habilidades e competências necessárias à formação de um profissional que atenda aos anseios da sociedade, 
principalmente pela desconexão existente com as discussões sobre questões políticas, econômicas, sociais e ambientais.

Pesquisa desenvolvida por Souza et al. (2015), com estudantes de engenharia de uma instituição pública do interior do estado de São Paulo, fornece elementos para concluir que, do ponto de vista dos estudantes,

[...] ainda se faz necessário desenvolver como um todo o conjunto de competências apresentadas pelas DCN, que ainda existe certa propensão a se desenvolver as habilidades técnicas e conteudistas em detrimento das demais em todo o conjunto. Consegue-se também sugerir que existe certa discrepância entre o que a universidade tem desenvolvido no aluno e o que as empresas têm considerado importante para esses profissionais (SOUZA et al., 2015, p. 29).

Algumas propostas têm surgido para implantar em cursos de engenharia disciplinas que possam gerar uma aproximação do ambiente acadêmico com situações reais do mercado de trabalho, buscando analisar criticamente o papel do profissional envolvido no processo, em seus diversos aspectos, éticos, políticos, sociais, econômicos, etc. (PEREIRA; BAZZO, 2008). Nesse contexto, destaca-se, novamente, o campo de estudos CTS, como forma de reunir elementos para análise (PEREIRA; BAZZO; LINSINGEN, 2000).

Neste artigo, busca-se contribuir para uma formação e atuação mais amplas do engenheiro; para isso, foi elaborada uma proposta didática com base em uma pesquisa delineada na forma de estudo de caso com análise qualitativa de dados. Ela foi desenvolvida em uma turma de engenharia de uma instituição particular do interior do estado de São Paulo. O objetivo foi mapear a inserção de um conjunto de atividades extracurriculares de cunho interdisciplinar, com base no campo de estudos CTS. Nessas atividades, fazem parte discussões sobre questões sociotécnicas controversas, visando romper com o modelo tradicional de ensino, tendo em vista que o estímulo dos raciocínios crítico e reflexivo, conforme sugere as DCNs, não pode ocorrer por meio de um ensino tradicional, com foco somente nas habilidades técnicas e conteudistas (PEREIRA; HAYASHI, 2016).

\section{Metodologia}

A proposta didática foi elaborada com base na análise de atividades desenvolvidas em uma turma de 41 estudantes do período diurno, envolvendo três cursos de engenharia: Mecânica, Produção e Química. Elas ocorreram em encontros quinzenais e em horários extraclasse, sendo que o pesquisador também atuou como professor de Física da turma, o que 
facilitou o contato entre as pessoas. Após um período de engajamento, 25 estudantes participaram da proposta completa, que foi desenvolvida ao longo do primeiro semestre de 2014. Em 2015, um segundo momento foi proposto como forma de complementar os dados obtidos.

Considerando a faixa etária e com um caráter exploratório, os estudantes envolvidos foram orientados a se agruparam espontaneamente, o que gerou sete equipes, sendo que cada uma se dedicou ao estudo de uma questão sociotécnica controversa de livre escolha. Os temas foram debatidos de acordo com um cronograma estabelecido, pois essa atividade concorria com as demais atividades curriculares dos estudantes. Foi preciso interromper o processo em períodos de prova. Os debates gerados foram gravados em vídeo e transcritos para análise.

Dentre as atividades propostas para o engajamento estão: discussões sobre o papel do engenheiro na sociedade, a influência da tecnologia e da inovação na vida das pessoas, a construção social da tecnologia e o significado de controvérsias científicas e tecnológicas. Textos, apresentações em Power Point e vídeos disponíveis na internet foram utilizados nessas atividades, que ocorreram antes da divisão da turma em equipes para a preparação dos debates na forma de fóruns simulados (PEREIRA; HAYASHI, 2016). O material foi disponibilizado aos estudantes em um grupo fechado no Facebook ${ }^{\circledR}$.

No segundo momento da pesquisa, em 2015, foi dada ênfase à construção da argumentação, identificando os principais elementos do discurso de cada ator nos debates, procurando melhorar seu poder de convencimento. Toulmin (2001) afirma que a maneira como os argumentos são utilizados para embasar uma conclusão varia muito de acordo com o contexto, entretanto, é possível encontrar estruturas invariáveis nesses argumentos, dentro de certos limites, bem como nos preceitos utilizados em suas críticas, por mais diferentes que sejam os campos de conhecimento.

Um esquema de argumento sofisticado é necessário para expor uma ideia com imparcialidade lógica e compreender adequadamente sua natureza (TOULMIN, 2001). No esquema proposto por Toulmin (2001), aqui denominado TAP (Padrão de Argumentos de Toulmin, na sigla em inglês), os fatos utilizados para fundamentar a conclusão (alegação) são denominados de dados e passam por algumas etapas. Nessas etapas encontram-se as afirmações ou hipóteses que dão suporte ao elo existente entre os dados e a conclusão (Figura 1). 
Figura 1 - Estrutura para análise TAP

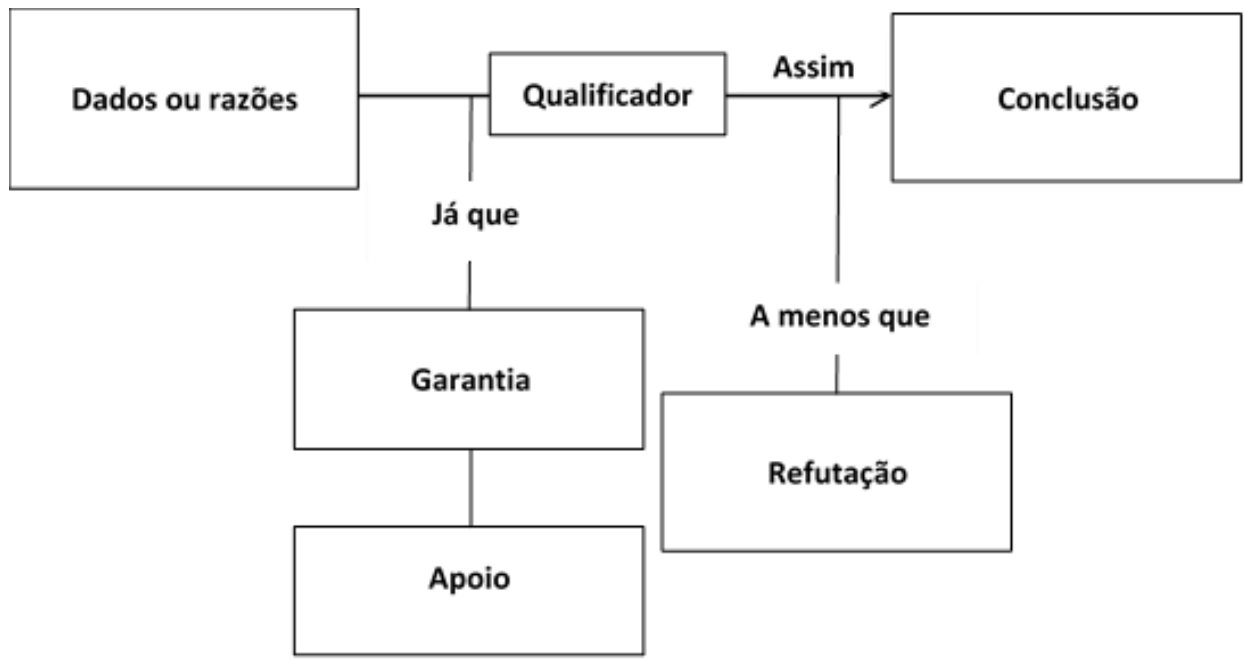

Fonte: Toulmin (2001)

Segundo Toulmin (2001), para que um argumento esteja completo é necessário fornecer mais detalhes sobre em quais situações a justificativa é válida. Assim, outros elementos podem ser incorporados para dar apoio à garantia (justificativa), principalmente utilizando aqueles que não são alvos de fortes questionamentos, como leis ou decretos. Da mesma forma, é possível acrescentar em quais situações a justificativa não é válida, ou seja, refutar uma ideia. O qualificador, elemento que aparece entre os dados e a conclusão, serve para indicar a força da conclusão, geralmente expresso por meio de termos como: necessariamente ou possivelmente.

A estratégia didática aqui proposta envolve debate sobre situações controversas e foi elaborada de acordo com uma estrutura simplificada de análise TAP, substituindo-se os elementos de garantia e apoio por um elemento denominado de justificativa, como propõem Silva, Scarpa e Trivelato (2013), tendo em vista algumas dificuldades encontradas na construção do esquema, em uma análise preliminar. Isso pode ter ocorrido pelo fato de se realizar uma análise interpretativa a partir de textos obtidos das transcrições dos vídeos, sem a preocupação inicial em preencher todos os elementos do TAP, mas deixando o debate fluir naturalmente entre os atores envolvidos.

\section{Resultados e discussões}

O desenvolvimento das atividades propostas buscou criar um ambiente propício à participação ativa dos estudantes e a prática da argumentação no ensino de engenharia, cuja motivação para os estudantes surgiu da oportunidade em escolherem temas de seus interesses, 
como a identificação e representação dos atores envolvidos nas situações de disputa, conforme as controvérsias abordadas.

A pesquisa por informações e a construção de melhores argumentos tornaram-se essenciais na busca pelo consenso. Entretanto, para fins pedagógicos neste trabalho, o estabelecimento do consenso não foi considerado tão importante, pois pode ser um processo muito demorado, se ocorrer ao longo de um semestre letivo. $\mathrm{O}$ debate de ideias foi o aspecto mais valorizado, pois ele pode proporcionar reflexões e análise, aprendizagem em ouvir argumentos opostos e, talvez, mudança de opinião em torno de um tema, o que pode ocorrer por meio da persuasão, sem a intenção de manipulação, mas de fornecer informações suficientes para a tomada de decisões melhores.

Dos sete temas abordados pelas equipes na pesquisa, um deles é apresentado neste artigo para exemplificar a proposta didática, uma vez que não é possível discutir todos eles aqui, dado o limite de espaço do artigo. O trabalho completo é apresentado na tese de doutorado defendida pelo primeiro autor.

O tema escolhido trata da implantação da usina solar de Ivanpah, que está localizada no deserto de Mojave, nos EUA, ocupando uma área de $16 \mathrm{~km}^{2}$, próxima da fronteira entre os estados da Califórnia e Nevada. Nesse caso, a controvérsia aborda uma reflexão que contrasta os impactos positivos e negativos do empreendimento.

Três empresas estão envolvidas no projeto, a Google, a NRG Energy e a Bright Source Energy. A usina funciona com um conjunto de 173,5 mil espelhos móveis espalhados por uma ampla área plana. Todos eles apontam para um mesmo ponto, o foco, situado no alto de três torres com 140 metros de altura. Nesse ponto, canalizações de água são aquecidas pela incidência da luz solar refletida, produzindo vapor que move uma turbina e que aciona um gerador de energia elétrica. A usina tem capacidade para produzir cerca de $400 \mathrm{MW}$ de potência, o suficiente para abastecer, aproximadamente, 140 mil casas nos EUA. Esses dados foram levantados pelos próprios estudantes.

No quadro 1, para exemplificar o procedimento de análise, são apresentados os principais argumentos utilizados pelo estudante que representou as empresas no debate. Além disso, uma análise foi realizada pelos autores deste artigo à luz de Giddens (2008). Os argumentos foram obtidos por meio da transcrição da gravação do debate em áudio e vídeo, como informado anteriormente. As transcrições foram disponibilizadas aos estudantes para que também pudessem construir os diagramas TAP. 
Quadro 1 - Principais argumentos do representante das empresas

\begin{tabular}{|c|c|}
\hline Principais argumentos & Análise \\
\hline $\begin{array}{l}\text { O principal objetivo é levar nossa indústria à } \\
\text { revolução de energia limpa, pois os } \\
\text { consumidores querem isso, as empresas } \\
\text { precisam e o nosso planeta exige, trabalhar para } \\
\text { minimizar o impacto da energia convencional, } \\
\text { optando-se pela energia limpa, potencializando } \\
\text { nossa frota de geração para atender a sociedade } \\
\text { e o cumprimento das normas ambientais. }\end{array}$ & $\begin{array}{l}\text { Nota-se a preocupação com questões } \\
\text { ambientais levantadas pelo representante das } \\
\text { empresas, uma preocupação cada vez mais } \\
\text { presente no mundo contemporâneo, que } \\
\text { exige reflexão sobre o impacto da tecnologia } \\
\text { na sociedade. }\end{array}$ \\
\hline $\begin{array}{l}\text { A usina poderá gerar } 30 \% \text { de toda energia solar } \\
\text { produzida atualmente nos Estados Unidos. As } \\
\text { obras foram iniciadas em } 2010 \text { e empregou } \\
\text { cerca de três mil trabalhadores. } \\
\text { [...] o grupo tem como primordial missão } \\
\text { corporativa ser o líder ambiental na área de } \\
\text { energia limpa. [...] Não nos envolvemos para } \\
\text { causar uma boa impressão em um jogo de } \\
\text { marketing [...] }\end{array}$ & $\begin{array}{l}\text { No final da década de } 1980 \text {, a ideia de } \\
\text { desenvolvimento sustentável passou a fazer } \\
\text { parte das discussões governamentais e } \\
\text { demais setores da sociedade. De acordo com } \\
\text { Giddens (2008), o desenvolvimento } \\
\text { sustentável é definido como o uso de } \\
\text { recursos renováveis para promover o } \\
\text { crescimento econômico, a proteção de } \\
\text { espécies animais e da biodiversidade e o } \\
\text { compromisso em manter água, terra e ar } \\
\text { limpos. Essa preocupação está presente na } \\
\text { Missão da empresa, de acordo com o } \\
\text { representante. }\end{array}$ \\
\hline $\begin{array}{l}\text { Com relação aos impactos ambientais, eu acho } \\
\text { que um projeto dessa escala, nem tudo é } 100 \% \\
\text { [...] em fase de testes, houve uma falha com } \\
\text { relação ao reflexo dos espelhos com os pilotos } \\
\text { de aviões [...] e a segunda com relação aos } \\
\text { pássaros está sendo estudado [...] (a empresa) } \\
\text { está sempre empenhada para melhorar, diminuir } \\
\text { esse impacto ambiental [...] }\end{array}$ & $\begin{array}{l}\text { O representante destaca a questão sobre } \\
\text { impactos ambientais e os riscos inerentes de } \\
\text { um projeto. De acordo com Giddens (2008), } \\
\text { as questões ambientais não estão } \\
\text { relacionadas exclusivamente a deterioração } \\
\text { do ambiente, mas também aos modos de vida } \\
\text { fomentados pela sociedade industrial. O que } \\
\text { leva a reflexões sobre uma nova forma de } \\
\text { consumo, preocupada com o impacto } \\
\text { ambiental gerado, tanto no processo de } \\
\text { produção quanto em relação ao lixo } \\
\text { produzido. }\end{array}$ \\
\hline
\end{tabular}

Fonte: Elaboração própria

A partir dos argumentos obtidos, cujo quadro 1 apresenta uma síntese, foi elaborado pelos pesquisadores um diagrama TAP para mapear o raciocínio lógico utilizado pelo representante das empresas, em defesa do ponto de vista desse ator (Figura 2). Além disso, a figura 3 apresenta o esquema construído pelo próprio estudante, segundo o modelo completo TAP, com o objetivo de estimular a elaboração do argumento de apoio, apesar de não se exigir a identificação de um qualificador, uma vez que não houve um momento específico na pesquisa para aprendizagem da construção do diagrama TAP, mas apenas algumas orientações. A complexidade do tema, identificada pela dificuldade dos estudantes de engenharia em elaborar o diagrama TAP completo, abre oportunidades para elaboração de minicursos ou oficinas para essa finalidade. 
Figura 2 - Diagrama TAP de acordo com os argumentos utilizados pelo representante das empresas

Dados

Conclusão

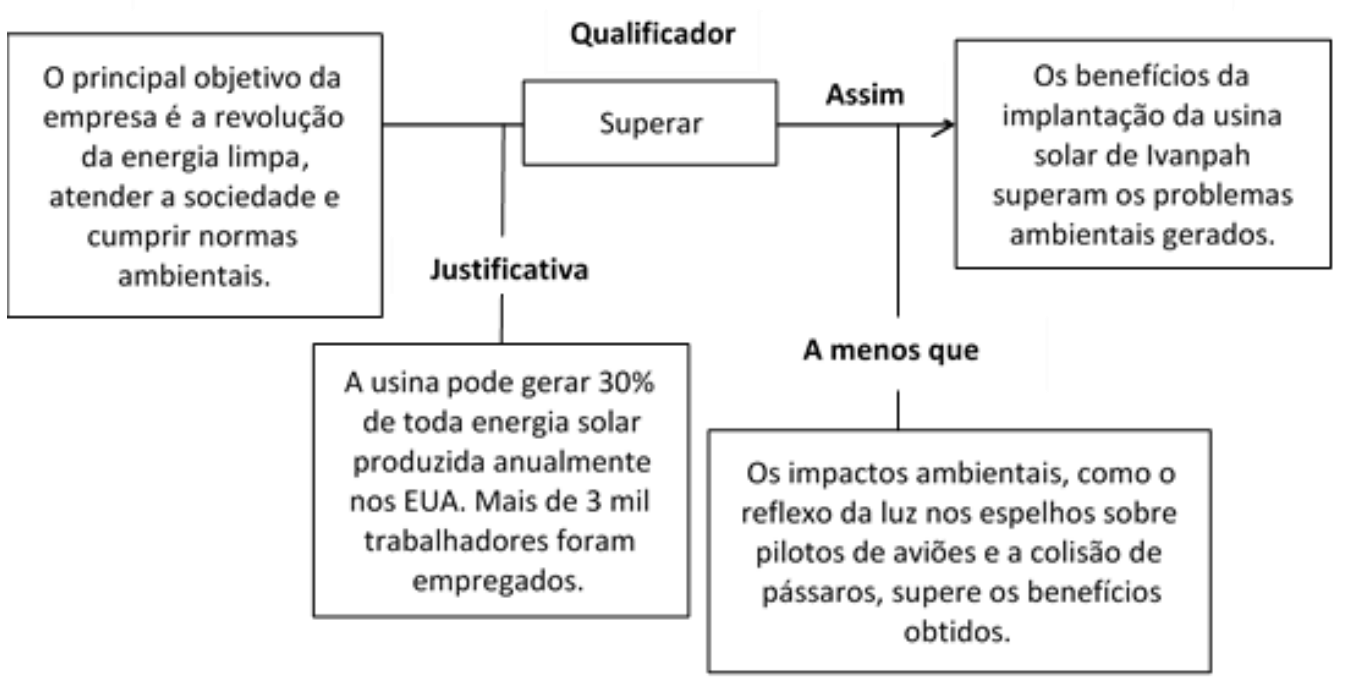

Fonte: Elaboração própria

Figura 3 - Diagrama TAP elaborado pelo representante das empresas Dados Conclusão

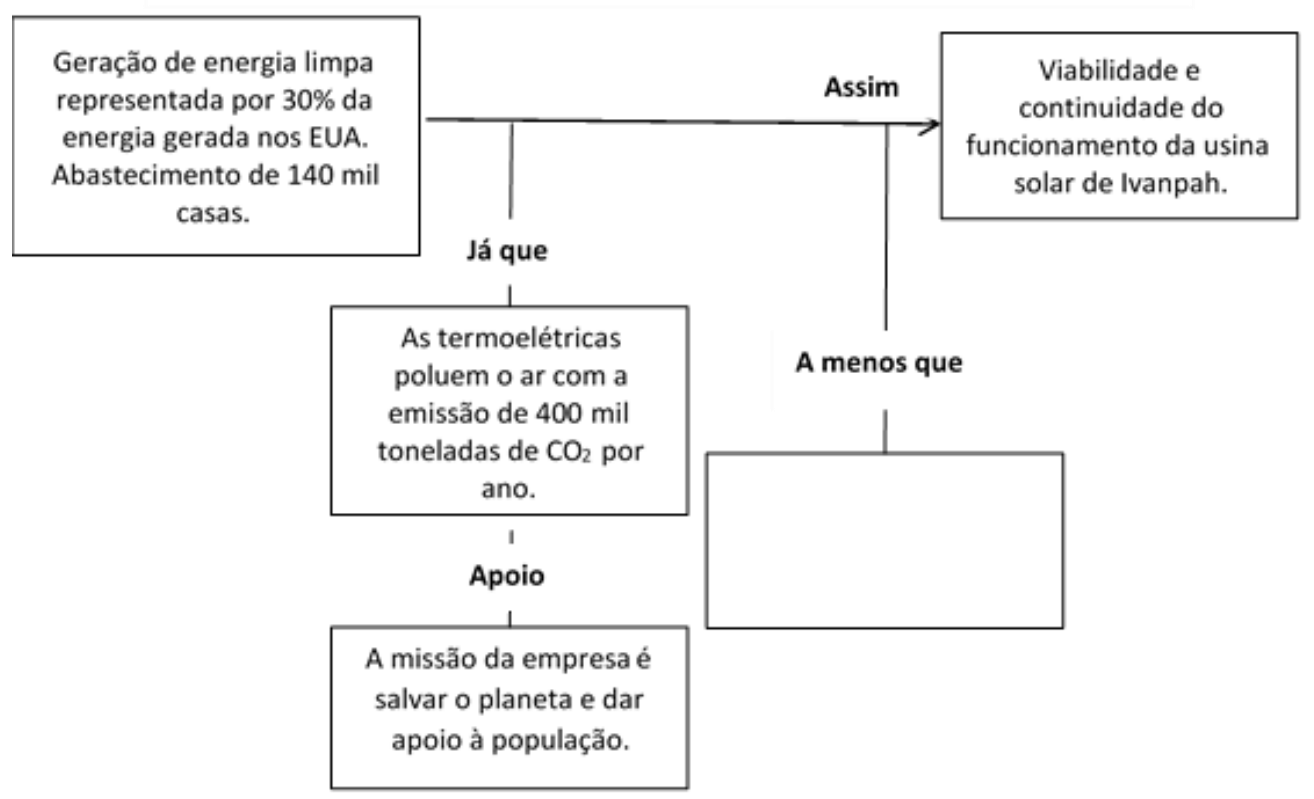

Fonte: Elaborado pelos estudantes

Comparando-se as figuras 2 e 3, nota-se que o representante das empresas não elabora o argumento de apoio ou a justificativa segundo as orientações de Toulmin (2001), nem reconhece argumentos de refutação em sua fala, apesar de indicar possíveis aspectos negativos no projeto, em termos de impacto ambiental. $\mathrm{O}$ argumento de apoio poderia ser melhor 
estruturado a partir de uma pesquisa sobre o relatório de impacto que serve de base para a aprovação do projeto. A falta de uma estrutura completa de argumentação fragiliza a conclusão, dando margem à falseabilidade.

$\mathrm{Na}$ estrutura proposta pelo representante das empresas (Figura 3) aparece como argumento de apoio a missão dessas empresas envolvidas no projeto, um documento pouco adequado para essa finalidade, uma vez que é elaborado pelos próprios interessados. O não reconhecimento de argumentos de refutação em seu discurso, ou sua devida valorização, reforça a concepção de que a visão determinista sobre tecnologia ainda está muito presente nos cursos de graduação em engenharia, como afirma Veraszto et al. (2013).

No quadro 2 são apresentados os principais argumentos que foram utilizados pelo representante dos biólogos e ativistas no debate. Em seguida, nas figuras 4 e 5 são apresentados os diagramas TAP, elaborados pelos autores e pelo estudante, respectivamente.

Quadro 2 - Principais argumentos do representante dos biólogos e ativistas

\begin{tabular}{|c|c|}
\hline Principais argumentos & Análise \\
\hline $\begin{array}{l}\text { [...] como toda nova tecnologia ela apresenta } \\
\text { alguns impactos ambientais, exemplo, tem os } \\
\text { pássaros, porque como os espelhos são voltados } \\
\text { bem para o Sol os raios refletidos são muito } \\
\text { fortes e quando o pássaro passa ele acha que é } \\
\text { um lago, ou seja, eles acabam mortos [...] E } \\
\text { também outra desvantagem são dos pilotos, } \\
\text { porque como eles vão pilotar na região, os raios } \\
\text { solares dão uma atrapalhada [...] }\end{array}$ & $\begin{array}{l}\text { O representante identifica alguns problemas } \\
\text { que essa tecnologia acarreta, embora Giddens } \\
(2008) \text { afirme que a noção de } \\
\text { desenvolvimento sustentável é demasiada } \\
\text { vaga, negligenciando as necessidades dos } \\
\text { países mais pobres, em detrimento daqueles } \\
\text { mais ricos. Sendo assim, cabe refletir sobre a } \\
\text { possibilidade de implantação de um projeto } \\
\text { desse porte em países pobres. }\end{array}$ \\
\hline $\begin{array}{l}{[\ldots] \text { os efeitos }} \\
\text { que dá uma cor } \\
\text { emissão de gas } \\
\text { estufa }[\ldots] \text { vai } \\
\text { casas }[\ldots]\end{array}$ & $\begin{array}{l}\text { O representante dos biólogos e ativistas se } \\
\text { mostra convencido dos benefícios das } \\
\text { empresas que administram a usina solar, } \\
\text { apesar de alguns impactos ambientais. }\end{array}$ \\
\hline
\end{tabular}

Fonte: Elaboração própria 
Figura 4 - Diagrama TAP de acordo com os argumentos utilizados pelo representante dos biólogos e ativistas

Dados

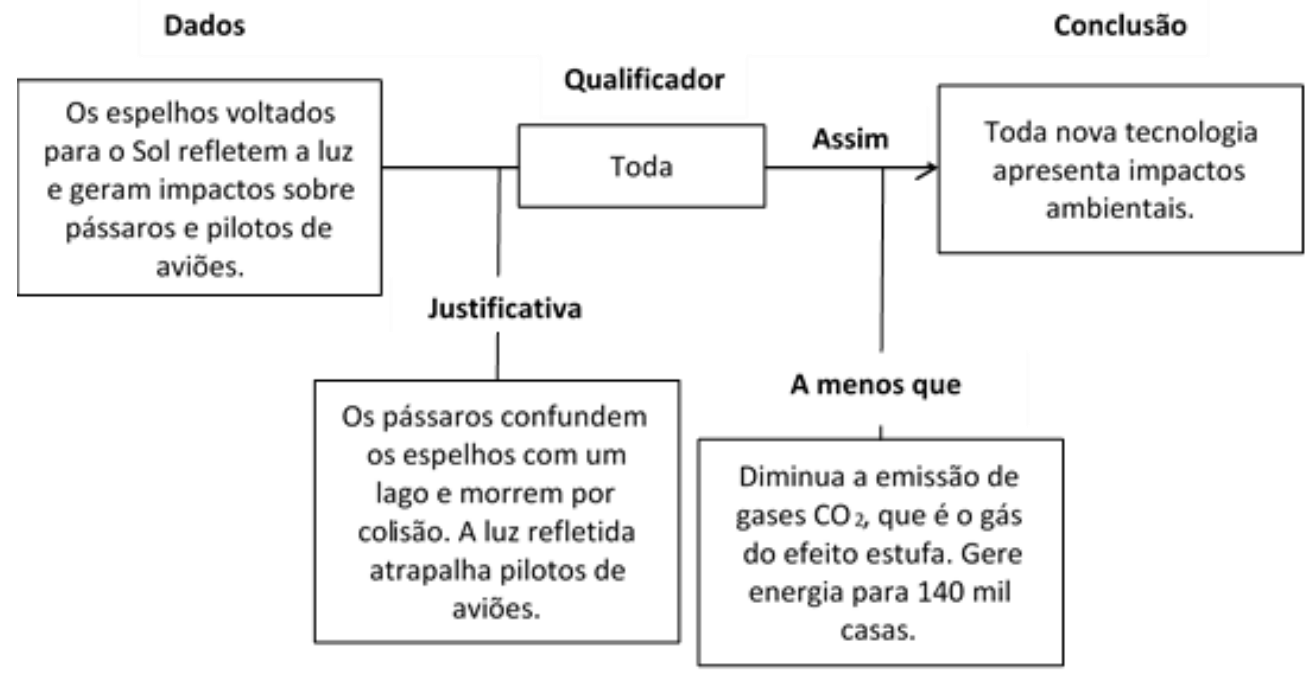

Fonte: Elaboração própria

Figura 5 - Diagrama TAP elaborado pelo representante dos biólogos e ativistas

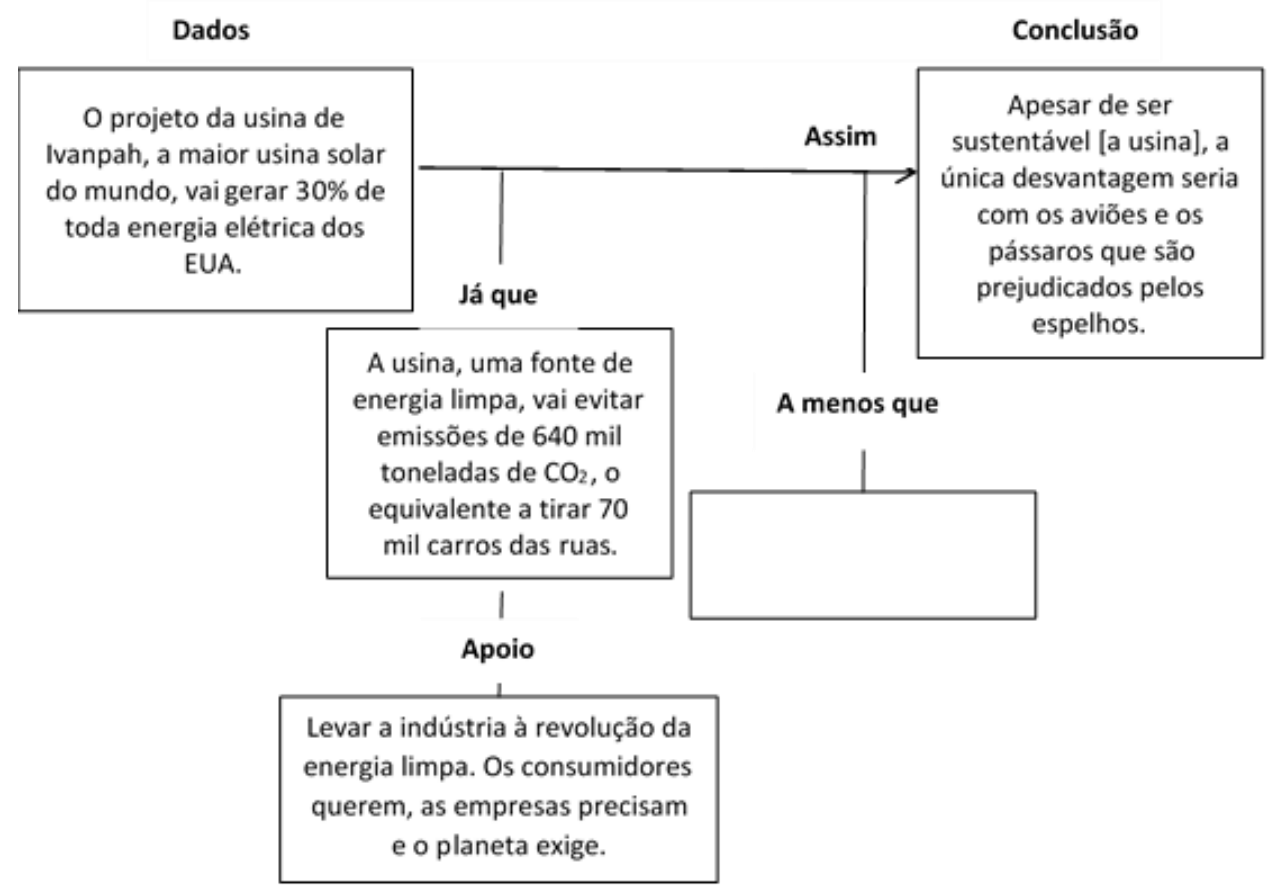

Fonte: Elaborado pelos estudantes

O representante dos biólogos e ativistas não deixa claro que os aspectos negativos apresentados, como o fato de a luz refletida pelos espelhos atrapalharem pilotos de avião e gerarem mortes de pássaros, podem ser argumentos de refutação à implantação do projeto. Por esse motivo, eles não foram incluídos em seu esquema TAP (Figura 5). Além disso, o 
representante usa argumentos de apoio semelhantes aos do representante das empresas, entretanto, falta elemento mais forte que possa fundamentar esse item, por exemplo, um relatório de impacto ambiental e/ou de análise econômica.

Esse representante também não reconhece o elemento de refutação em sua fala, reforçando a concepção de que o pensamento determinista da tecnologia paira entre os estudantes de engenharia, ou seja, parece que a tecnologia se desenvolve de forma linear, como se não fosse possível interferir no processo por meio de tomadas de decisão.

No quadro 3, são apresentados os principais argumentos que foram utilizados pelo representante do governo no debate. Em seguida, nas figuras 6 e 7, são apresentados os diagramas TAP elaborados pelos autores e pelo representante, respectivamente.

Quadro 3 - Principais argumentos do representante do governo

\begin{tabular}{|c|c|}
\hline Principais argumentos & Análise \\
\hline $\begin{array}{l}\text { [...] a construção da usina foi um } \\
\text { investimento muito benéfico, para o estado e } \\
\text { para o país [...] é energia limpa, causa muito } \\
\text { menos impacto ambiental se for comparar com } \\
\text { os outros tipos de obtenção da mesma energia, } \\
\text { se comparar com uma usina hidroelétrica, tem } \\
\text { que inundar certa área que vai matar a fauna da } \\
\text { região [...] }\end{array}$ & $\begin{array}{l}\text { A inovação científica e tecnológica traz } \\
\text { muitos benefícios à sociedade, como destacado } \\
\text { pelo representante. Entretanto, de acordo com } \\
\text { Giddens (2008), também pode causar muitos } \\
\text { problemas e incertezas, sendo um desafio } \\
\text { encontrar o ponto de equilíbrio entre benefícios } \\
\text { potenciais e desastres possíveis. }\end{array}$ \\
\hline $\begin{array}{l}\text { Eu não sabia o que era o contra } \\
\text { (aspectos), para mim tudo era a favor. }\end{array}$ & $\begin{array}{l}\text { O representante do governo não } \\
\text { percebe os aspectos contrários à implantação de } \\
\text { uma tecnologia até esse momento do debate. }\end{array}$ \\
\hline $\begin{array}{l}\text { Para o consumidor, vai ser uma energia } \\
\text { um pouco mais cara. }\end{array}$ & $\begin{array}{l}\text { O alto custo da energia elétrica } \\
\text { produzida pela usina solar, soma-se aos demais } \\
\text { impactos ambientais. Aspectos que foram aos } \\
\text { poucos sendo reconhecidos pelo representante, } \\
\text { no decorrer do debate. }\end{array}$ \\
\hline
\end{tabular}

Fonte: Elaboração própria 
Figura 6 - Diagrama TAP de acordo com os argumentos utilizados pelo representante do governo

Dados

Conclusão

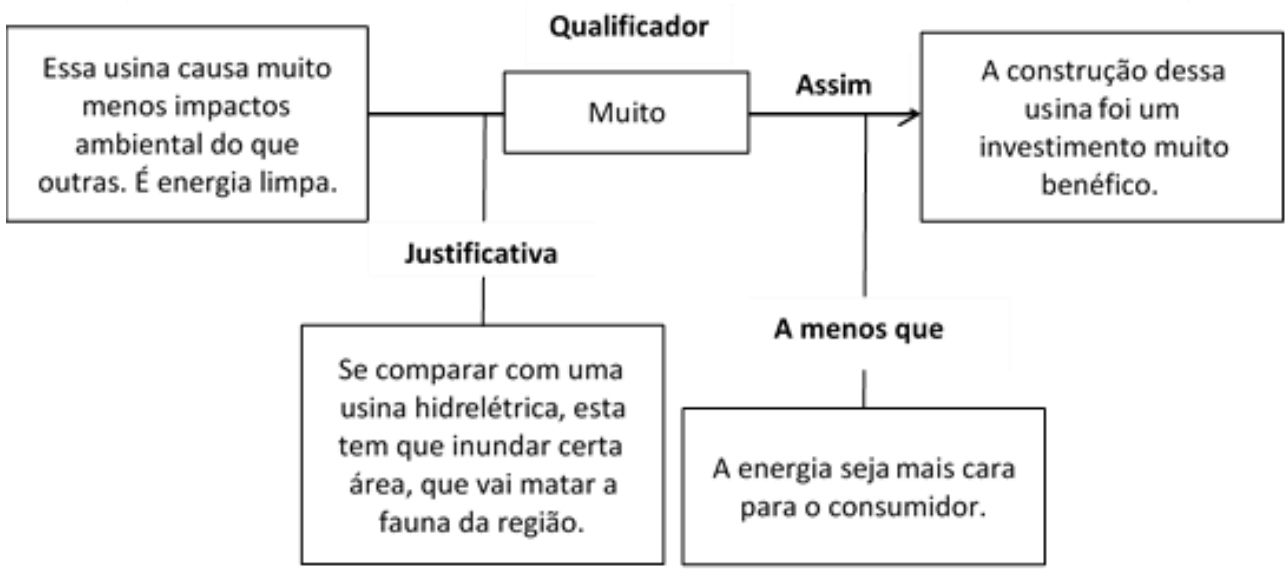

Fonte: Elaboração própria

Figura 7 - Diagrama TAP elaborado pelo representante do governo

Dados

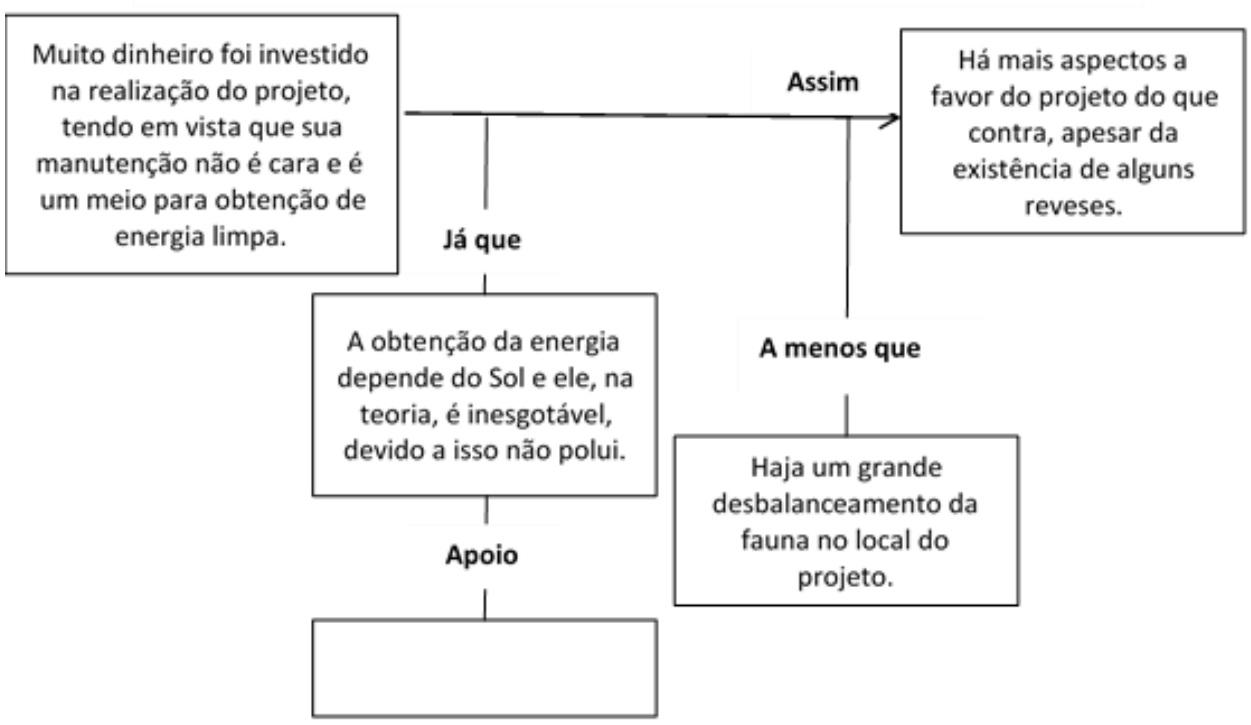

Fonte: Elaborado pelo estudante

Assim como nos demais diagramas, nota-se a fragilidade na construção da argumentação, o que reforça a necessidade em se trabalhar especificamente esses aspectos no ambiente educacional, voltado às discussões interdisciplinares na análise de projetos de engenharia que envolvam questões sociotécnicas controversas.

Assim, a proposta didática foi elaborada ao longo do processo, cuja síntese é apresentada no quadro 4. Quatro etapas foram essenciais na proposta, uma destinada ao engajamento dos estudantes em atividades extraclasse, uma para definição dos grupos e das questões sociotécnicas controversas, uma para o levantamento das informações necessárias à construção 
da argumentação para o debate e uma para o conhecimento da estrutura argumentativa de Toulmin, visando à elaboração de melhores propostas e, consequentemente, melhorar o convencimento.

No caso da pesquisa, houve também a preocupação com a coleta de dados, com o objetivo de fundamentar a elaboração da proposta e posterior difusão do conhecimento.

A ideia desse passo a passo não é fornecer uma "receita de bolo", mas apontar um caminho viável como o que foi utilizado na pesquisa com essa turma de estudantes de engenharia e não apenas idealizado. Espera-se que ela possa contribuir para fornecer elementos ao desenvolvimento de atividades semelhantes, de acordo com o contexto local, considerando e respeitando as experiências e trajetórias dos profissionais envolvidos em sua implantação.

\section{Quadro 4 - Síntese da proposta didática}

\begin{tabular}{|c|c|}
\hline Etapas & Descrição \\
\hline Engajamento & $\begin{array}{l}\text { Esta etapa inicial tem como principal objetivo envolver os estudantes da turma, } \\
\text { caso a atividade seja proposta de forma extracurricular, mostrando sua } \\
\text { importância para a formação em engenharia. Nela apresentam-se as diretrizes } \\
\text { curriculares, com destaque para uma visão crítica e reflexiva e as perspectivas } \\
\text { profissionais para o mundo contemporâneo, indicando uma visão ampliada da } \\
\text { profissão de engenheiro. Além disso, procura-se dar uma ideia de todas as } \\
\text { etapas da proposta, para que o estudante possa avaliar a viabilidade de sua } \\
\text { participação. }\end{array}$ \\
\hline $\begin{array}{l}\text { Definiçãa dos } \\
\text { grupos e temas } \\
\text { sociotécnicos } \\
\text { controversos }\end{array}$ & $\begin{array}{l}\text { Nesta etapa procura-se apresentar o significado do que seja um tema } \\
\text { sociotécnico controverso, dando algum exemplo, como os alimentos } \\
\text { transgênicos ou a energia nuclear, para que os estudantes, divididos em grupo, } \\
\text { proponham temas de seu interesse, ou seja, relacionados com o curso de } \\
\text { engenharia no qual estejam vinculados, podendo valorizar aspectos regionais. } \\
\text { A liberdade de escolha do tema entre os estudantes atua como forma de imbuir } \\
\text { responsabilidade ao trabalho que será desenvolvido. A partir desta etapa os } \\
\text { estudantes trabalham em grupo de forma ativa, pois são os protagonistas da } \\
\text { proposta. }\end{array}$ \\
\hline $\begin{array}{l}\text { Levantamento } \\
\text { de } \\
\text { informações } \\
\text { sobre os temas } \\
\text { escolhidos }\end{array}$ & $\begin{array}{l}\text { Nesta etapa os estudantes buscam identificar os atores envolvidos na temática } \\
\text { sociotécnica que será analisada. Os estudantes são orientados para que façam } \\
\text { um levantamento de informações que possam dar sustentação aos argumentos } \\
\text { utilizados pelos atores, de acordo com os pontos de vista destes. É salutar que } \\
\text { se oriente para a obtenção de dados como relatórios, leis e decretos, ou seja, } \\
\text { documentos que possam dar forte sustentação ao argumento do ator, buscando } \\
\text { o convencimento em torno da questão abordada. }\end{array}$ \\
\hline Debate & $\begin{array}{l}\text { O debate no formato de fórum de negociações é idealizado para que cada } \\
\text { estudante represente um ator. O ambiente, na pesquisa, foi organizado de tal } \\
\text { modo que os atores foram identificados por meio de uma "placa" sobre a mesa } \\
\text { do professor em uma sala de aula comum, ficando dispostos em forma de } \\
\text { semicírculo. O debate foi gravado em vídeo e depois transcrito. Isso foi } \\
\text { importante não somente para reunir dados para pesquisa, mas também para } \\
\text { valorizar a fala dos estudantes e possibilitar a reapresentação dos debates, com }\end{array}$ \\
\hline
\end{tabular}




\begin{tabular}{|l|l|}
\hline Etapas & \multicolumn{1}{c|}{ Descrição } \\
\hline & $\begin{array}{l}\text { todos os grupos participantes, em um momento posterior. Com isso, foi } \\
\text { possível rever e avaliar a fala dos atores. } \\
\text { É importante que o professor fique atento aos principais argumentos e } \\
\text { elementos que possam emergir dos debates, como ocorreu na pesquisa, em que } \\
\text { os estudantes afirmaram que coloca em risco sua posição na empresa, ou } \\
\text { mesmo o emprego, quando defendem ideias que consideram opostas ao que } \\
\text { presumivelmente servem para defender os interesses dessa empresa, mesmo } \\
\text { contrariando seus pontos de vista como cidadão. Esta etapa é o ponto alto da } \\
\text { proposta, sendo que o mais importante não é estabelecer um consenso, mas } \\
\text { criar um ambiente de debate, estimulando a construção de bons argumentos e } \\
\text { a atitude de ouvir ideias convergentes e/ou divergentes de forma democrática } \\
\text { e respeitosa. }\end{array}$ \\
\hline $\begin{array}{l}\text { Es resultados da pesquisa indicaram que os estudantes apresentam muitas } \\
\text { dificuldades na construção de argumentos convincentes e fortes. Dessa forma, } \\
\text { criar estratégias de aprendizagem utilizando, por exemplo, o Padrão de } \\
\text { Argumentos de Toulmin } \\
\text { Argumentos de Toulmin como referência pode contribuir na melhoria dos } \\
\text { argumentos, tornando-os menos falseáveis. Além disso, com tal estrutura, } \\
\text { podem-se difundir com maior coerência as ideias apresentadas no debate, a } \\
\text { partir das discussões geradas em torno de questões sociotécnicas controversas. }\end{array}$ \\
\hline
\end{tabular}

Fonte: Elaboração própria

\section{Considerações finais}

A estrutura de debate indicada neste artigo buscou criar um ambiente propício à participação ativa do estudante e à prática da argumentação no ensino de engenharia, com a oportunidade de escolha espontânea dos temas, assim como a formação dos grupos, a identificação e a representação dos atores envolvidos em situações sociotécnicas controversas.

$\mathrm{Na}$ pesquisa, alguns estudantes apresentaram dificuldades em argumentar de maneira contrária às suas próprias convicções, o que corrobora com o trabalho de Kolstoe (2000). Espera-se que a análise de tais situações no ambiente acadêmico possa contribuir para a compreensão, reflexão e, em alguns casos, aceitação do ponto de vista de outra pessoa, tendo em vista um contexto social mais amplo.

A fragilidade da argumentação, em diversos casos, tanto em termos da estrutura lógica como da base teórica, propicia oportunidades para se ampliar e amadurecer a discussão do processo, a fim de contribuir para a superação das dificuldades encontradas, tendo em vista a formação de um profissional de engenharia melhor preparado, principalmente em termos de sua formação humanística, com uma visão ampliada de seu papel na sociedade.

Os resultados indicam a necessidade de continuidade de estudos e reflexões sobre questões tecnológicas, visando, principalmente, a elaboração de materiais instrucionais para melhorar as capacidades de reflexão e argumentação dos estudantes de engenharia, obtendo-se 
argumentos mais complexos na análise de temas controversos e o impacto dos projetos para a sociedade.

Nesse sentido, uma ferramenta virtual proposta por Silva, Moura e Terramatte (2015) pode ser muito útil, pois com ela procura-se evitar alguns aspectos presentes em argumentos frágeis, facilmente falseáveis, como a ausência de dados, dados irrelevantes ou deficientes, suposições injustificadas ou ambiguidade. Pinto et al. (2018) também recomendam o uso do modelo de argumentos de Toulmin, bem como a ferramenta virtual LiteMap para visualizar graficamente a estrutura argumentativa utilizada pelos atores envolvidos no processo, assim como para facilitar uma reflexão sobre tal estrutura.

O debate com esse formato demonstra ter potencial para uma poderosa estratégia didática com o objetivo de discutir questões sociotécnicas entre estudantes de engenharia, valorizando reflexões sob um ponto de vista interdisciplinar, na tentativa de romper com uma visão determinista sobre tecnologia, ainda muito presente no ensino de engenharia. Espera-se com isso poder estimular a participação ativa do estudante, fortalecendo o poder da argumentação em um debate democrático de ideias, podendo incluir teorias que abordam questões sobre o desenvolvimento científico e tecnológico na sociedade, além da construção argumentativa em si.

Embora a implantação dessa estratégia no currículo regular, principalmente no período noturno, ainda apresente grandes desafios, por demandar um esforço a mais em relação à participação dos estudantes nas atividades extracurriculares, a associação do esquema de debate com o diagrama TAP mostra-se um instrumento promissor para estruturar a discussão de questões interdisciplinares.

Nesse sentido, o campo de estudos CTS pode fornecer elementos importantes de análise, visando estimular os raciocínios crítico e reflexivo em cursos de engenharia, ou em diversos níveis educacionais, considerando o exercício da cidadania em uma sociedade democrática. Bijker (2017) afirma que, para se construir um mundo de forma que as próximas gerações consigam lidar com os grandes desafios e conflitos que emergem na sociedade, é preciso investir na produção de conhecimento, nas instituições sociais, nos mecanismos de deliberação democrática, como conselhos consultivos, jornalismo de alta qualidade, diálogos públicos sobre ciência e tecnologia, ou seja, é necessária uma sociedade civil forte e participativa.

AGRADECIMENTOS: Aos estudantes de engenharia que participaram do projeto e à instituição de ensino que permitiu seu desenvolvimento. 


\section{REFERÊNCIAS}

ABET. Criteria for accrediting engineering programs. Engineering Accreditation Commission, Baltimore, MD, USA, 2014. Disponível em: http://www.abet.org/wpcontent/uploads/2015/05/E001-15-16-EAC-Criteria-03-10-15.pdf. Acesso em: 28 jun. 2017.

BAZZO, W . A. Ciência, tecnologia e sociedade e o contexto da educação tecnológica. 2. ed. Florianópolis: Ed. UFSC. 2010.

BIJKER, W. E. Constructing Worlds: Reflections on Science, Technology and Democracy (and a Plea for Bold Modesty). Engaging Science, Technology, and Society, n. 3, p. 315331, 2017. Disponível em: https://estsjournal.org/index.php/ests/article/view/170/96. Acesso em: 13 mar. 2018.

BRASIL. CNE/CES 11. Diretrizes Curriculares Nacionais do Curso de Graduação em Engenharia. Brasília: Ministério da Educação, 2002. Disponível em:

http://portal.mec.gov.br/cne/arquivos/pdf/CES112002.pdf. Acesso em: 08 fev. 2017.

FAZENDA, I. C. A. Interdisciplinaridade - transdisciplinaridade: visões culturais e epistemológicas. In: (Org.) O que é interdisciplinaridade? São Paulo: Cortez, 2008.

GIDDENS, A. Sociologia. 6. ed. Lisboa: Fundação Calouste Gulbenkian, 2008.

KLINE, R. R. To teach engineering ethics. IEEE Technology and Society Magazine. v. 20, n. 4, p. 13-20, 2001. Disponível em: http://user.das.ufsc.br/ moreno/

seguranca/etica/00974503.pdf. Acesso em: 28 jun. 2016.

KOLSTOE, S. D. Consensus projects: teaching science for citizenship. International Journal of Science Education, v. 22, n. 6, p. 645 - 664. 2000. Disponível em: https://doi.org/ 10.1080/095006900289714. Acesso em: 15 out. 2016.

PEREIRA, L. T. V.; BAZZO, W. A. Introdução à engenharia: conceitos, ferramentas e comportamentos. In: XXXVI COBENGE, 2008, São Paulo - SP. Anais... Brasília: ABENGE, 2008. Disponível em: http://www.abenge.org.br/cobenge/arquivos/11/artigos/3351.pdf. Acesso em: 13 mar. 2015.

PEREIRA, L. T. V.; BAZZO, W. A.; LINSINGEN, I. Uma disciplina CTS para os cursos de engenharia. In: XXVIII COBENGE, 2000, Ouro Preto - MG. Anais... Brasília: ABENGE, 2000. Disponível em: http://www.abenge.org.br/cobenge/arquivos/19/artigos/466.pdf. Acesso em: 20 jun. 2014.

PEREIRA, V. R. A; HAYASHI, C. R. M. Fóruns de Negociações Simulados no Ensino de Engenharia: Análise de uma estratégia didática. Revista Iberoamericana de Ciencia, Tecnología y Sociedad, v. 11, n. 33. 2016. Disponível em: http://www.revistacts.net/volumen -11-numero-33/322-dossier-cts/747-foruns-de-negociacoes-simulados-no-ensino-deengenharia-analise-de-uma-estrategia-didatica. Acesso em: 22 set. 2016.

PINTO, S. M. C. et al. Argumentação de estudantes da educação básica sobre dilemas sóciocientíficos no projeto ENGAGE. RIAEE - Revista Ibero-Americana de Estudos em Educação, Araraquara, v. 13, n. 1, p. 207-228, 2018. Disponível em: 
https://periodicos.fclar.unesp.br/iberoamericana/article/download/10242/7155. Acesso em: 12 abr. 2018.

SILVA, N.; MOURA, J.; TERRAMATTE, P. ARG: a virtual tool for teaching argumentation theory. CoRR, p. 207-214, 2015. Disponível em: https://arxiv.org/pdf/1507.03682v1.pdf. Acesso em: 03 jan. 2017.

SILVA, R. P. O.; SCARPA, D. L.; TRIVELATO, S. L. F. Proposta de validação de metodologia de análise de argumentos escritos de acordo com o TAP. In: IX ENCONTRO NACIONAL DE PESQUISA EM EDUCAÇÃO EM CIÊNCIAS - IX ENPEC, 2013, Águas de Lindóia-SP. Atas... Águas de Lindóia: ABRAPEC, 2013, p. 1-8. Disponível em: http://www.nutes.ufrj.br/abrapec/ixenpec/atas/resumos/R0704-1.pdf. Acesso em: 10 fev. 2017.

SOUZA, A. P. A. et al. A valorização das competências na formação e na atuação de engenheiros: a visão de estudantes de uma instituição pública. Revista de Ensino de Engenharia. v. 34, n. 2, p. 19-30, 2015. Disponível em: http://www.bibliotekevirtual.org/ revistas/ABENGE/v34n02/v34n02a03.pdf. Acesso em: 12 jan. 2018.

TOULMIN, S. E. Os usos do argumento. São Paulo: Martins Fontes, 2001.

VERASZTO, E. V. et al. Concepções de tecnologia de graduandos do Estado de São Paulo e suas implicações educacionais: breve análise a partir de modelagem de equações estruturais. Ciência \& Educação, Bauru, v. 19, n. 3, p. 761-779, 2013. Disponível em: http://www.scielo.br/pdf/ciedu/v19n3/15.pdf. Acesso em: 10 abr. 2016.

\section{Como referenciar este artigo}

PEREIRA, Vágner Ricardo de Araújo.; HAYASHI, Carlos Roberto Massao. Controvérsias sociotécnicas: uma proposta didática para o ensino de engenharia. Revista Ibero-Americana de Estudos em Educação, Araraquara, v. 14, n. 2, p. 526-542, abr./jun., 2019. E-ISSN: 19825587. DOI: $10.21723 /$ riaee.v14i2.11374

Submetido em: 16/05/2018

Revisões Requeridas: 20/07/2018

Aprovado em: 29/07/2018 